RACIC 5 (1) (2020)
JURNAL RAB CONTRUCTION RESEARCH
UNIVERSITAS
ABDURRAB

\title{
POTENSI PENGENDALIAN ON STREET PARKING DI RUAS JALAN DAMAR KOTAPADANG
}

\author{
Angelalia Roza $^{1,}$ Andi Mulya Rusli ${ }^{2,}$ Vino Febrian Putra ${ }^{3}$ \\ ${ }^{1}$ Program Studi Teknik Sipil, Institut Teknologi Padang \\ Jl. Kandis Raya No.6, Kota Padang, Sumatera Barat 25173 \\ *email : angelaliaroza@gmail.com \\ ${ }^{2}$ Kementrian Pekerjaan Umum dan Perumahan Rakyat, Indonesia \\ ${ }^{3}$ Mahasiswa Program Studi Teknik Sipil, Institut Teknologi Padang \\ Jl. Kandis Raya No.6, Kota Padang, Sumatera Barat 25173
}

\section{Info Artikel \\ Sejarah Artikel: Diterima Oktober 2019 \\ Disetujui Mei 2020 \\ Dipublikasikan Juni 2020}

Keywords : Kapasitas Ruas Jalan, Karakteristik on Street Parking, dan Tingkat Pelayanan

\section{Abstrak}

Ruas jalan Damar merupakan laluan penghubung kawasan pasar Kota Padang mulai terindikasi mengalami masalah parkir. Indikatornya adalah gangguan arus dan penumpukkan volume parkir yang cukup tinggi di ruas Jalan Belakang Olo. Ini diduga akan berdampak pada penurunan tingkat pelayanan jalan (level of service ) di ruas Jalan Damar Padang. Maka telah dilakukan pendekatan analisis kapasitas, karakteristik parkir dan manajemen perpakiran di ruas Jalan Damar. Hasil analisis karakteristik parkir selama tiga hari pengamatan menunjukkan durasi parkir rata-rata 34-35 menit, Parking Turn Over maksimum 3,6 kend/hari/ruang, dan Indeks Parkir maksimum 84,91\%. Hasil analisis tingkat pelayanan di Jalan Damar ternyata menunujukkan nilai derajat kejenuhan bernilai 0,51 (DS < 0.80) dan masih termasuk dalam klasifikasi pelayanan B dengan ciri - ciri arus stabil dan kecepatan perjalanan rata - rata $\geq$ $40 \mathrm{~km} / \mathrm{jam}$. Hasil trend analisys volume lalu lintas dan volume kendaraan parkir adalah berbanding terbalik. Hal ini menjawab pertanyaan mengapa pola kegiatan on street parkir di ruas Jalan Damar saat ini tidak menimbulkan masalah berarti. Pengendalian on street parking mungkin melalui alat mesin meter parkir pada lokasi ini direkomendasikan. Pada tahap preliminary, hasil analisis karakteristik parkir dan lay out on street parking yang ditawarkan dapat dijadikan pertimbangan bagi pihak yang berkepentingan. Namun perlu dikaji lebih lanjut regulasi tarif dengan pertimbangan laju pertumbuhan kendaraan agar tidak berdampak pada penurunan tingkat pelayanan pada kawasan kajian dikemudian hari.

Kata Kunci: Kapasitas Ruas Jalan, Karakteristik on Street Parking, dan Tingkat Pelayanan
Abstract
The Damar road section is a connecting lane for the Pasar Raya Padang area which starting to face parking problem. The indicator is the disruption of the flow and the high accumulation of parking volume on Jalan Belakang Olo section. These affected to the decrease on the level of the road services (LOS) on Jalan Damar Padang. So, the analysis of LOS, parking characteristics and parking management on Jalan Damar were carried out. The results of the 
parking characteristics analysis during the three days of observation showed that the average parking duration was 34-35 minutes, the maximum Parking Turn Over was 3.6 vehicles /day/space, and a maximum Parking Index was 84.91 $\%$. The level of service level value indicated that the degree of saturation was 0.51 (DS <0.80) and it categorized to the B level; the flow classified stable with the average travel speeds $\geq 40 \mathrm{~km} / \mathrm{hr}$. The results of the traffic volume analysis trends and the volume of parked vehicles are contradictory. This could answer the question why that on parking activities the Jalan Damar did not caused a significant problem. Management of the on street parking through a Parking Meter Machine at this location is recommended. In the initial stage, the results of the parking characteristics analysis and the lay-out of parking lot can be offered. However, the further study will be needed to determined such as the vehicles growth rate and parking tariff to avoid the impact on the Level of Service.

Keywords: Road Capacity, on Street Parking Characteristics, and Level of Service

(C) 2020 Universitas Abdurrab

Alamat korespondensi:

Jl. Kandis Raya No.6,

ISSN 2527-7073

Kota Padang, Sumatera Barat 25173

*email : angelaliaroza@gmail.com

\section{PENDAHULUAN}

Berdasarkan Perda Kota Padang, No. 4 Tahun 2012 tentang "Rencana Tata Ruang Wilayah Kota Padang", Jalan Damar yang terletak di Kelurahan Olo, Kecamatan Padang Barat merupakan kawasan perdagangan Kota Padang. Namun kawasan ini telah berkembang pesat. Ruas jalan Damar turut disibukkan oleh aktivitas Pelayanan kesehatan, aktivitas pendidikan dan aktivitas wisata. Penyediaan sarana penunjang seperti penyediaan fasilitas pejalan kaki, pemberhentian angkutan kota serta tempat parkir harus dikondisikan sedemikian rupa, sehingga tidak mengganggu aktivitas pergerakan di kawasan ini. Pada sisi kiri dan kanan ruas jalan Damar ini sering dijumpai praktek on street parking dengan kecenderungan aktivitas parkir yang lebih tinggi pada ruas kanan dari pada ruas kiri. Penyebabnya adalah saat ini sisi Kanan ruas jalan Damar dipadati bangunan seperti Rumah Sakit Mata (Padang Eye Center), Ace Hardware Plaza, Dealer Motor Yamaha, Yayasan Pendidikan Baiturrahmah, distro dan Toko Buku Gramedia (Gambar 1). Sedangkan Ruas kiri Jalan Damar saat ini dipadati bangunan pertokoan seperti toko bangunan, toko barang elektronik, kedai makanan, dan Damar Plaza.
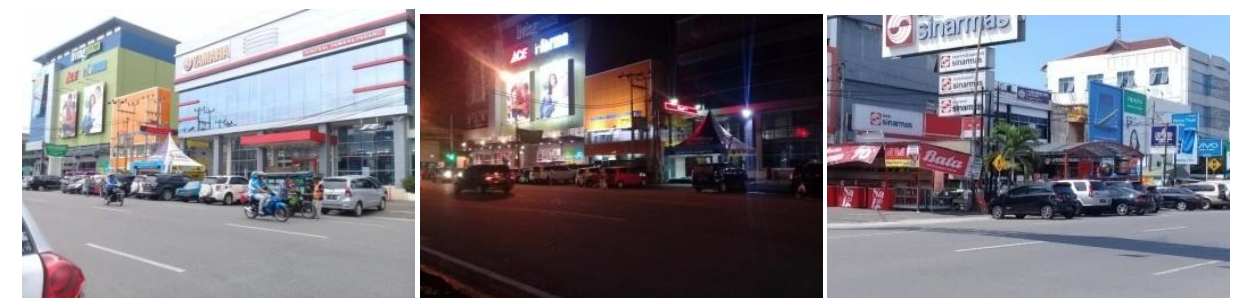

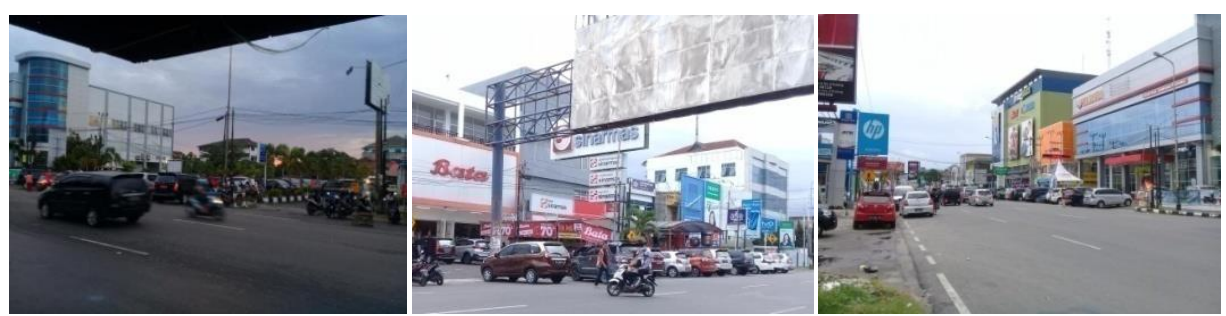

Gambar 1. Aktivitas on Street Parking di Ruas Jalan Damar

(Sumber : Survei Lapangan, 2019)

Dari preliminary survey, ditemui fenomena parkir yang unik di kawasan ini. Meski lahan parkir khusus (off street parking) telah tersedia, tepatnya di samping kanan toko buku Gramedia. Namun pengguna kendaraan bermotor lebih memilih memarkirkan kendaraannya di badan jalan (on street parking). Kendaraan umum (taksi online) juga sering melakukan parkir on street dengan durasi lebih dari 20 menit. Perilaku parkir kendaraan di kawasan ini menarik untuk dikaji lebih lanjut.

\section{METODE}

\section{Tahapan Pengumpulan Data}

Data untuk keperluan penelitian dibedakan atas data primer dan data sekunder. Khusus data primer dikumpulkan melalui survey, yang dibedakan atas tiga kelompok berikut (Roza, 2018; Guvil, 2018):

- Pertama survey volume lalu lintas untuk pengumpulan data volume lalu lintas. Data volume kendaraan yang dimaksud adalah kendaraan yang melewati ruas jalan Damar. Dilakukan survey pengambilan data volume aktual kendaraan pada jam puncak. Survey volume dilakukan pada hari libur dan hari kerja karena di prediksi dapat mewakili kepadatan volume lalu lintas mingguan. Pencatatan volume lalu lintas dilakukan pada hari libur (sabtu dan minggu) untuk melihat trend dan menjaga kekurasian data. Data arus yang melewati ruas jalan Damar tersebut dikumpulkan sejalan dengan data kondisi geometrik ruas jalan Damar dan Data hambatan samping untuk faktor penyesuaian kapasitas.

- Kedua, survey parkir untuk pengumpulan data parkir pada penelitian ini hanya berupa kendaraan roda empat saja. Dilakukan pencatatan kendaraan parkir (nomor Polisi kendaraan) setiap 15 menit dari pukul $12.00 \mathrm{WIB}$ hingga $21.00 \mathrm{WIB}$, selama 3 hari pada hari 2 libur (Sabtu dan Minggu) serta 1 hari kerja (Rabu). Data yang diambi dalam pengamatan tersebut dianggap dapat merepresentasikan jumlah kendaraan parkir terendah dan tertinggi dalam satu minggu. 
- Ketiga, survey kuisioner / paper based untuk mengkaji implementasi manajemen parkir dari sudut pandang pengguna. Data dikumpulkan melalui penyebaran kuisioner terhadap 100 responden Perhitungan jumlah sampel dilakukan dengan menggunakan rumus Slovin. Untuk komparasi, dilakukan pula wawancara semi terstruktur terhadap pihak ace hardware plaza serta juru parkir sebagai informan.

\section{Tahapan Rekapitulasi Data}

Berikutnya dilakukan tahapan rekapitulasi data. Data yang telah diperoleh dari survey primer di atas selanjutnya direkapitulasi dan ditabulasi sesuai kelompok data masing-masing, sebagai berikut (Roza, 2018; Guvil, 2018):

- Data volume lalu lintas yang terkumpul selama tiga hari pengamatan ditabulasi dan dikelompokkan ke dalam 3 rentang pengamatan (13.00-14.00; 14.00-15.00 dan 15.0016.00).

- Data aktual plat nomor kendaraan parkir yang telah dicatat per-15 menit; selama 9 jam per hari; untuk 3 hari pengamatan, kemudian data direkapitulasi dan ditampilkan dalam bentuk grafik.

- Data kuisioner dari responden terkait aspek manajemen perkir diolah melalui analisis persepsi

\section{Tahapan Analisa Data}

Data yang telah direkapitulasi di atas selanjutnya diolah dan dianalisis seperti terlihat pada flowchart Penelitian (Gambar 2) dengan rinci sebagai berikut (Roza, 2018; Guvil, 2018):

- Tahap 1, Rekapitulasi data volume lalu lintas kendaraan dan data Kapasitas ruas jalan selanjutnya dianalisis untuk mendapatkan nilai Derajat Kejenuhan (DS) yang diukur dari rasio arus terhadap kapasitas. Pada tahap Selanjutnya nilai derajat kejenuhan (DS) akan bandingkan; ketika kondisi ideal dan ketika adanya aktivitas on street parking.

- Tahap 2, Data kendaraan parkir yang telah ditabulasi. Kemudian dilakukan perhitungan kapasitas menggunakan metode analisis kapasitas (MKJI 1997). Selanjutnya dideskripsikan Karakteristik parkir meliputi; volume parkir, akumulasi parkir, durasi parkir, Parking Turn Over, kapasitas parkir, indeks parkir dan kebutuhan ruang parkir.

- Tahap 3, Data kuisioner diolah melalui analisis persepsi. Pengujian validitas instrument dilakukan melalui uji korelasi Pearson Product Moment. Uji reabilitas instrumen diukur melalui Cronbach Alpha. Hasil analisis kapasitas, analisis kinerja lalu lintas, analisis data persepsi dan hasil wawancara dengan petugas parkir dihubungkan untuk penarikan kesimpulan dan rekomendasi akhir terhadap manajemen parkir di kawasan kajian. 


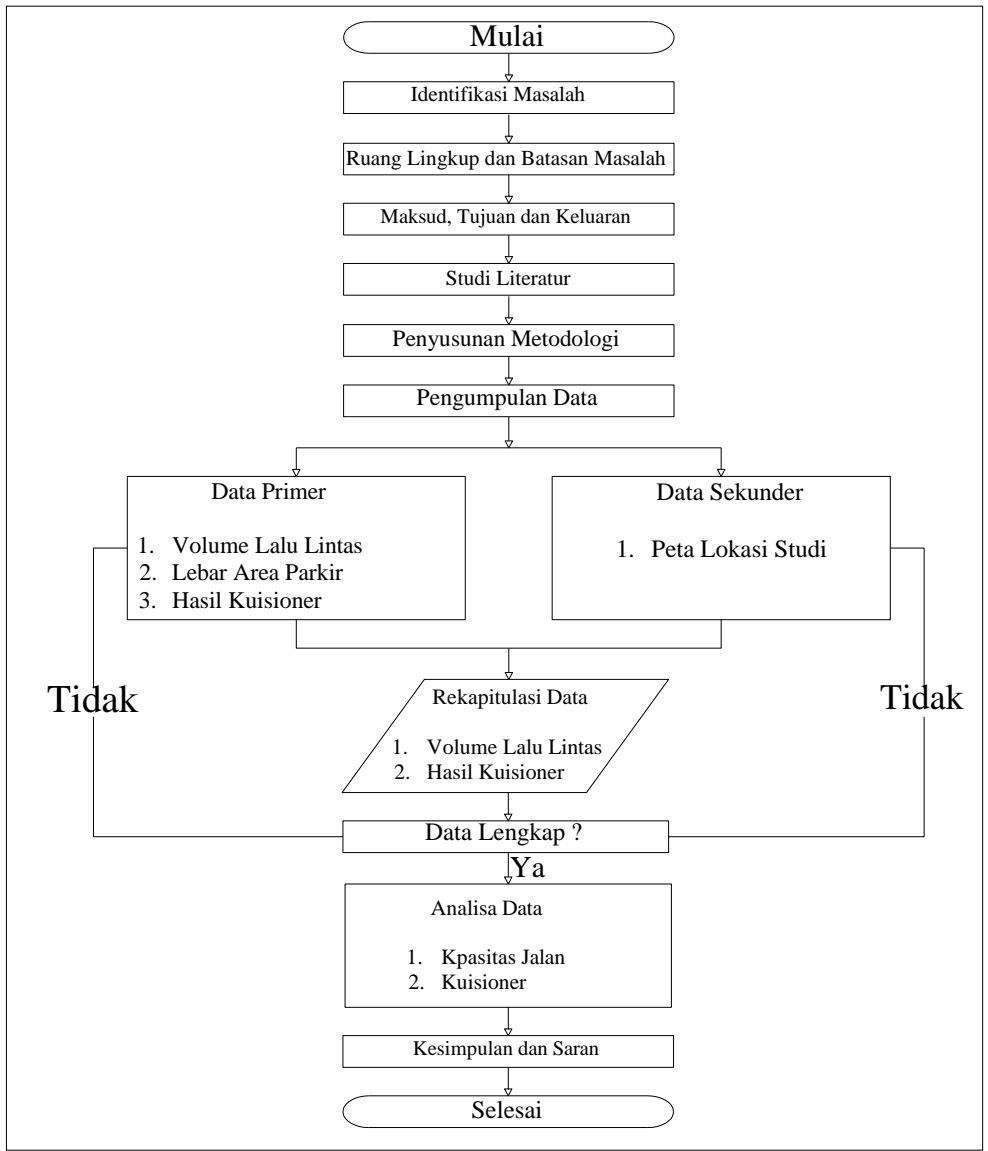

Gambar 2. Flowchart Penelitian

\section{HASIL DAN PEMBAHASAN}

\section{Analisis volume dan Kapasitas Ruas Jalan Damar}

Survei volume lalu lintas di ruas jalan Damar telah dilakukan selama 3 hari (Rabu, Sabtu dan Minggu) mulai pukul 09.00 WIB - 20.00 WIB. Dari hasil survey volume lalu lintas di kawasan kajian diketahui puncak lalu lintas harian terjadi pada siang - sore hari (13.00 - 16.00 WIB) (Gambar 3).

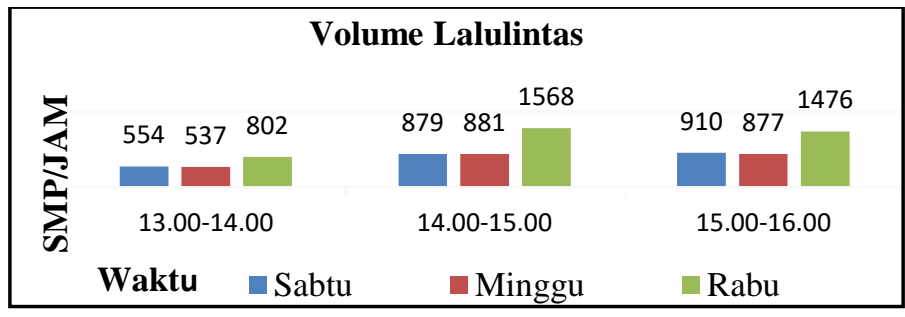

Gambar 3. Volume Lalulintas Ruas Jalan Damar (Sumber : Data Lapangan, 2019)

Terdapat perbedaan yang cukup signifikan antara volume lalu lintas pada hari kerja dan hari libur. Dimana pada hari kerja ruas jalan Damar ini selalu dipadati oleh kendaraan yang 
menuju pusat kota Padang (Pasar Raya Padang). Sementara, pada hari libur volume kendaraan tidak terlalu tinggi akibat kecenderungan pengendara untuk memilih rute melewati jalan Samudera (kawasan wisata Kota Padang). Kenyataannya telah terjadi penurunan kapasitas ruas Jalan Damar yang cukup berarti (46.24\%) dari 5717,27 smp/jam menjadi 3073,80 smp/jam akibat kegiatan on street parking Di kedua sisi badan jalan, pada ruas Jalan Damar. Level of Service (LOS) dan Derajat Kejenuhan (DS)

Selama pengamatan 3 (tiga) hari survey di lapangan, kendaraan yang melakukan aktivitas parkir on street telah ikut berperan menjadi hambatan samping (kondisi 1). Telah terjadi pengurangan kapasitas akibat kendaraan parkir di kedua sisi jalan selama tiga hari pengamatan. Saat Kapasitas ruas jalan Damar dihitung 5717,27 smp/jam didapatkan nilai derajat kejenuhan (DS) maksimum sebesar 0.27 ( Tabel 1). Merujuk MKJI (1997) dengan nilai derajat kejenuhan (DS $0.27<0,80$ (kondisi 1), maka ruas jalan ini termasuk pada klasifikasi A yang memiliki ciri - ciri dimana kondisi arus bebas dengan kecepatan lalu lintas $\geq 80 \mathrm{~km} / \mathrm{jam}$ dan volume lalu lintas sekitar $30 \%$ dari kapasitas jalan.

Tabel 1. Kondisi (1) DS Ruas Jalan Damar tanpa Optimalisasi Alat meter Parkir

\begin{tabular}{|c|c|c|c|c|c|}
\hline \multirow{2}{*}{ Hari } & Waktu & Total Kedua Arah & $\begin{array}{c}\text { Total } \\
\text { Kend. }\end{array}$ & Kapasitas & DS \\
\hline \multirow{3}{*}{ Sabtu } & $13.00-14.00$ & Simp. Olo-Simp. A.Yani \& Simp. A.Yani - Simp. Olo & 554 & 5717.268 & 0.10 \\
\cline { 2 - 7 } & $14.00-15.00$ & Simp. Olo-Simp. A.Yani \& Simp. A.Yani - Simp. Olo & 879 & 5717.268 & 0.15 \\
\cline { 2 - 7 } & $15.00-16.00$ & Simp. Olo-Simp. A.Yani \& Simp. A.Yani - Simp. Olo & 910 & 5717.268 & 0.16 \\
\hline \multirow{3}{*}{ Minggu } & $13.00-14.00$ & Simp. Olo-Simp. A.Yani \& Simp. A.Yani - Simp. Olo & 537 & 5717.268 & 0.09 \\
\cline { 2 - 7 } & $14.00-15.00$ & Simp. Olo-Simp. A.Yani \& Simp. A.Yani - Simp. Olo & 881 & 5717.268 & 0.15 \\
\cline { 2 - 7 } & $15.00-16.00$ & Simp. Olo-Simp. A.Yani \& Simp. A.Yani - Simp. Olo & 877 & 5717.268 & 0.15 \\
\hline \multirow{3}{*}{ Rabu } & $13.00-14.00$ & Simp. Olo-Simp. A.Yani \& Simp. A.Yani - Simp. Olo & 802 & 5717.268 & 0.14 \\
\cline { 2 - 7 } & $14.00-15.00$ & Simp. Olo-Simp. A.Yani \& Simp. A.Yani - Simp. Olo & 1568 & 5717.268 & 0.27 \\
\cline { 2 - 6 } & $15.00-16.00$ & Simp. Olo-Simp. A.Yani \& Simp. A.Yani - Simp. Olo & 1476 & 5717.268 & 0.26 \\
\hline
\end{tabular}

(Sumber : Data Lapangan, 2019)

Namun aktivitas kendaraan parkir (Kondisi 2) telah mengakibatkan pengurangan kapasitas menjadi 3073,80 smp/jam, sehingga berdampak pada penurunan nilai Derajat Kejenuhan maksimum menjadi DS $=0,51$ (Tabel 2), Akan Tetapi ruas Jalan Damar ini ternyata masih mampu menampung volume kendaraan yang melewatinya dan memberikan tingkat pelayanan yang baik (DS $0.51<0,80$ ) Menurut klasifikasi tingkat pelayanan (MKIJI, 1997) ruas jalan ini termasuk pada klasifikasi B yang memiliki ciri - ciri dimana kondisi arus stabil dengan kecepatan lalu lintas $\geq 40 \mathrm{~km} / \mathrm{jam}$ dan volume lalu lintas sekitar $50 \%$ dari kapasitas jalan.

Tabel 2. Kondisi (2) Dugaan DS Ruas Jalan Damar dengan Optimalisasi Alat Meter Parkir 


\begin{tabular}{|c|c|c|c|c|c|}
\hline \multirow{2}{*}{ Hari } & Waktu & Total Kedua Arah & $\begin{array}{c}\text { Total } \\
\text { Kend. }\end{array}$ & Kapasitas & DS \\
\hline \multirow{4}{*}{ Sabtu } & $13.00-14.00$ & Simp. Olo-Simp. A.Yani \& Simp. A.Yani - Simp. Olo & 554 & 3104.54 & 0.18 \\
\cline { 2 - 7 } & $14.00-15.00$ & Simp. Olo-Simp. A.Yani \& Simp. A.Yani - Simp. Olo & 879 & 3104.54 & 0.28 \\
\cline { 2 - 7 } & $15.00-16.00$ & Simp. Olo-Simp. A.Yani \& Simp. A.Yani - Simp. Olo & 910 & 3104.54 & 0.29 \\
\hline \multirow{3}{*}{ Minggu } & $13.00-14.00$ & Simp. Olo-Simp. A.Yani \& Simp. A.Yani - Simp. Olo & 537 & 3104.54 & 0.17 \\
\cline { 2 - 7 } & $14.00-15.00$ & Simp. Olo-Simp. A.Yani \& Simp. A.Yani - Simp. Olo & 881 & 3104.54 & 0.28 \\
\cline { 2 - 7 } & $15.00-16.00$ & Simp. Olo-Simp. A.Yani \& Simp. A.Yani - Simp. Olo & 877 & 3104.54 & 0.28 \\
\hline \multirow{3}{*}{ Rabu } & $13.00-14.00$ & Simp. Olo-Simp. A.Yani \& Simp. A.Yani - Simp. Olo & 802 & 3104.54 & 0.26 \\
\cline { 2 - 7 } & $14.00-15.00$ & Simp. Olo-Simp. A.Yani \& Simp. A.Yani - Simp. Olo & 1568 & 3104.54 & 0.51 \\
\cline { 2 - 7 } & $15.00-16.00$ & Simp. Olo-Simp. A.Yani \& Simp. A.Yani - Simp. Olo & 1476 & 3104.54 & 0.48 \\
\hline
\end{tabular}

Sumber : Data Lapangan, 2019

\section{Analisis Karakteristik Parkir}

Kecenderungan pola parkir pengendara roda empat dikawasan ini adalah parkir on street. Saat ini pola park and ride belum menjadi pertimbangan bagi sebagian besar pengendara roda empat di kawasan kajian. Maka pengendalian on street parking yang mungkin dilakukan adalah dengan penerapan alat parkir meter. Penggunaan alat parkir meter dapat membantu manajemen perparkiran on street sekaligus berpotensi meningkatkan PAD Kota Padang (Roza, 2018). Maka untuk mengkaji potensi pengendalian on street parking dikawasan kajian, perlu diamati terlebih dahulu karakteristik parkirnya.

\section{Akumulasi Parkir}

Akumulasi parkir merupakan banyaknya kendaraan yang parkir disuatu lokasi parkir pada selang waktu tertentu. Survei yang dilakukan selama 9 jam dengan interval waktu pengambilan data 1 x 15 menit yang dimulai dari pukul 12.00 WIB sampai pukul 21.00 WIB. Akumulasi Perkir maksimum selama 3 (Tiga) hari pengamatan dapat dilihat pada Tabel 3.

Tabel 3. Akumulasi Parkir Maksimum ruas Jalan Damar

\begin{tabular}{ccccc}
\hline Hari & Waktu & $\begin{array}{c}\text { Akumulasi Parkir } \\
\text { Maksimum } \\
\text { Ruas Kiri }\end{array}$ & Waktu & $\begin{array}{c}\text { Akumulasi Parkir } \\
\text { Maksimum } \\
\text { Ruas Kanan }\end{array}$ \\
\hline Rabu & $14.30-14.45$ & 16 & $15.30-15.45$ & 33 \\
Sabtu & $17.45-18.00$ & 20 & $20.30-20.45$ & 40 \\
Minggu & $15.30-15.45$ & 15 & $18.00-18.15$ & 45 \\
\hline
\end{tabular}

Sumber : Hasil Analisa Data Survei, 2019

Dari hasil survey selama 9 (Sembilan) jam mulai pukul 12.00 WIB - 21.00 WIB terlihat bahwa akumulasi parkir kendaraan roda empat maksimum terjadi pada hari Minggu. Ruas yang 
paling dipadati on street parking adalah sisi kanan ruas Jalan Damar) sekitar pukul 18.00 WIB 18.15 WIB dengan jumlah kendaraan parkir sebanyak 45 kendaraan (Tabel 4).

Lebih detail trend akumulasi kendaraan parkir di sisi kanan Ruas jalan Damar selama 3(tiga) hari pengamatan dapat dilihat melalui Gambar 4.2. Pada hari kerja (Rabu) aktivitas on street parking yang tinggi diamati terjadi pada siang sampai dengan sore hari. Karena aktivitas pendidikan, aktivitas pelayanan kesehatan dan sebagian aktivitas perdagangan di lokasi kajian hanya beroperasi pada jam kerja. Sedangkan, pada Sabtu dan Minggu akumulasi parkir yang tinggi terjadi jurtru pada sore dan malam hari. Karena kawasan ini terdapat plaza dan pertokoan yang menjadi tarikan perjalanan di akhir pekan yang beroperasi hingga malam hari.

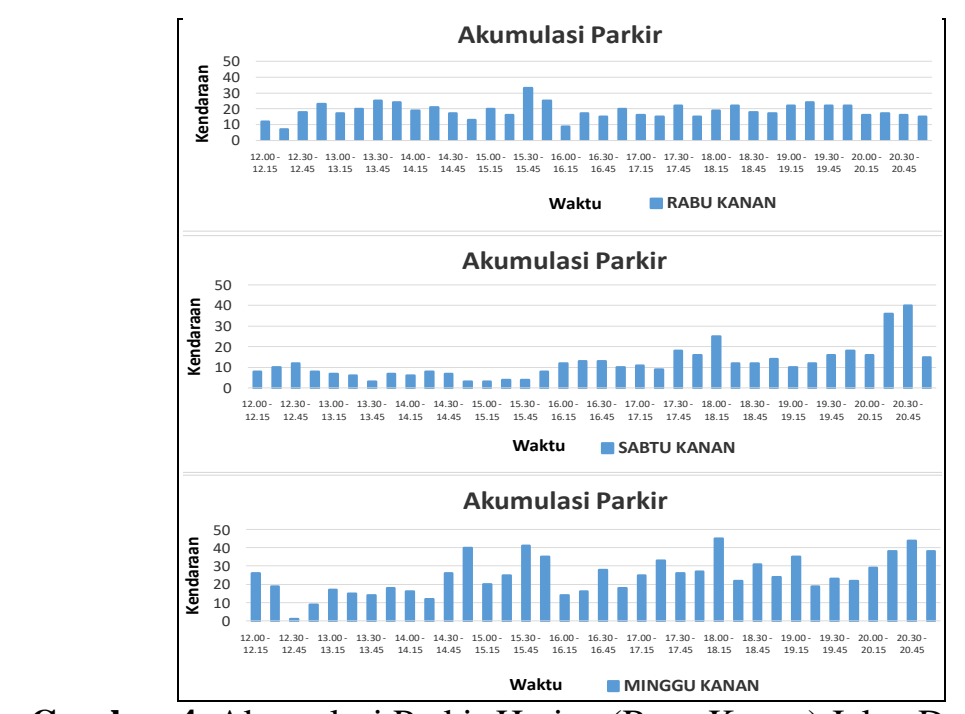

Gambar 4. Akumulasi Parkir Harian (Ruas Kanan) Jalan Damar (Sumber : Data Lapangan, 2019)

\section{Volume dan Durasi Parkir}

Pada ruas Jalan Damar Volume parkir dihari libur cenderung lebih tinggi tinggi dari pada di hari kerja terutama di sisi kanan ruas jalan Damar. Volume parkir maksimum terjadi hari Minggu dengan total 264 kendaraan parkir.

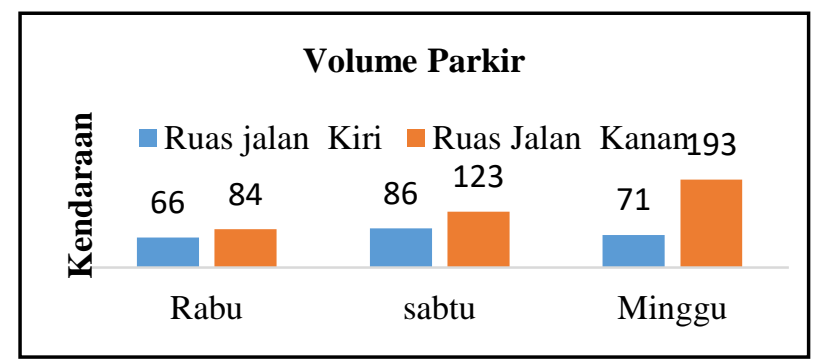

Gambar 5. Volume Parkir di Ruas Jalan Damar (Sumber : Hasil Analisa Data Survei, 2019) 
Tabel 4. Rekapitulasi Durasi Parkir

\begin{tabular}{|c|c|c|c|c|c|}
\hline \multirow{2}{*}{ Ruas Jalan } & \multirow{2}{*}{ Hari } & Jumlah & Total Durasi & Durasi Parkir & Rata-Rata Durasi \\
\cline { 3 - 5 } & & Kendaraan & ( Menit ) & Rata-Rata (Menit) & Parkir (Total) \\
\hline \multirow{3}{*}{ Ruas Kiri } & Rabu & 66 & 2745 & 41.59 & \multirow{2}{*}{35.05} \\
\cline { 2 - 5 } & Sabtu & 86 & 3540 & 41.16 & \\
\cline { 2 - 5 } & Minggu & 71 & 1590 & 22.39 & \multirow{2}{*}{33.72} \\
\hline \multirow{3}{*}{$\begin{array}{c}\text { Ruas } \\
\text { Kanan }\end{array}$} & Rabu & 84 & 2505 & 29.82 & \\
\cline { 2 - 5 } & sabtu & 123 & 4710 & 38.29 & \\
\cline { 2 - 5 } & Minggu & 193 & 6375 & 33.03 & \\
\hline
\end{tabular}

Sumber : Hasil Analisa Data Survei, 2019

Dapat diamati kecenderungan trend volume parkir (Gambar 5) dan trend volume lalu lintas (Gambar 3) yang terjadi di ruas Jalan Damar adalah berbanding terbalik. Dimana, volume lalulintas tertinggi pada hari kerja sementara volume parkir yang tinggi terjadi pada hari libur. Berdasarkan pengamatan penulis, volume lalulintas yang cukup tinggi terjadi pada siang dan sore hari karena ruas jalan Damar ini merupakan laluan penghubung menuju kawasan pasar raya padang. Sementara volume parkir justru cenderung tinggi pada sore dan malam hari, karena masyarakat cenderung parkir dan berbelanja di kawasan ini pada sore dan malam hari. Jika diamati lebih lanjut, ternyata durasi parkir rata-rata kendaraan roda empat pada ruas kanan berlangsung sekitar 35 menit. Dan pada ruas kiri berlangsung sekitar 34 menit (Tabel 4). Artinya pengguna parkir pada ruas Jalan Damar Padang cenderung tidak memerlukan waktu lama untuk berbelanja atau menyelesaikan keperluan lainnya dikawasan ini. Apabila dikaitkan hasil analisis volume lalu lintas dengan analisis volume parkir, maka terjawablah pertanyaan mengapa aktivitas on street parking di ruas jalan Damar tidak menimbulkan gangguan yang berarti terhadap kinerja lalu lintas. Jawabannya adalah karena di kawasan ini trend volume kendaraan pada hari libur tidak sepadat hari kerja sedangkan trend volume parkir pada hari libur cenderung lebih padat dari pada hari kerja.

\section{Tingkat Pergantian Parkir (Parking Turn Over)}

Saat ini belum tersedia lay out on street parking di ruas Jalan Damar. Dalam perhitungan Tingkat turnover parkir, diasumsikan terdapat 84 petak parkir untuk kendaraan roda empat pada ruas jalan Damar (Tabel 5). Asumsi tersebut didasarkan pengamatan bahwa 53 petak dapat disusun pada ruas kanan (arah Jl.Veteran - Jl.Pemuda) dan 31 petak pada ruas kiri (arah Jl.Pemuda - Jl.Veteran). Tingkat Turn Over parkir kendaraan roda empat maksimum terjadi pada ruas kanan (Minggu) sebesar 3,64 kend/hari/ruang (Tabel 5).

Tabel 5. Tingkat Pergantian Parkir (Parking Turn Over)

\begin{tabular}{|c|c|c|c|c|c|c|}
\hline \multirow{3}{*}{ Hari } & \multicolumn{3}{|c|}{ Turn Over Ruas Kiri } & \multicolumn{3}{c|}{ Turn Over Ruas Kanan } \\
\cline { 2 - 7 } & Volume & Jumlah Petak & PTO & Volume & Jumlah & PTO \\
\hline
\end{tabular}




\begin{tabular}{|c|c|c|c|c|c|c|}
\hline & & & & & Petak & \\
\hline Rabu & 66 & \multirow{3}{*}{31} & 2.13 & 84 & \multirow{2}{*}{53} & 1.58 \\
\hline Sabtu & 86 & 2.77 & 123 & & 2.32 \\
\hline Minggu & 71 & & 2.29 & 193 & & 3.64 \\
\cline { 1 - 1 } & & & & & \\
\hline
\end{tabular}

Sumber : Hasil Analisa Data, 2019

\section{Indeks Parkir}

Indeks parkir pada ruas Jalan Damar Padang dapat dilihat pada Tabel 6. Dapat diamati Indeks Parkir (IP) maksimum terjadi pada hari Minggu dengan Nilai IP $\max =84,91 \%$

Tabel 6.Indeks Parkir

\begin{tabular}{|c|c|c|c|c|}
\hline Lokasi Parkir & Hari & $\begin{array}{l}\text { Akumulasi } \\
\text { Maksimum }\end{array}$ & $\begin{array}{l}\text { Jumlah } \\
\text { Petak }\end{array}$ & $\operatorname{IP}(\%)$ \\
\hline \multirow{3}{*}{ Ruas Kiri (Veteran - Pemuda) } & Rabu & 16 & \multirow{3}{*}{31} & 51.61 \\
\hline & Sabtu & 20 & & 64.52 \\
\hline & Minggu & 15 & & 48.39 \\
\hline \multirow{3}{*}{ Ruas Kanan (Pemuda- Veteran) } & Rabu & 33 & \multirow{3}{*}{53} & 62.26 \\
\hline & Sabtu & 40 & & 75.47 \\
\hline & Minggu & 45 & & 84.91 \\
\hline
\end{tabular}

Sumber : Hasil Analisa Data Survei, 2019

Nilai IP $<100 \%$ tersebut menggambarkan bahwa Kebutuhan ruang parkir on street masih lebih rendah dari pada Daya tamping parkir yang tersedia. Artinya belum terjadi permasalahan serius akibat kegiatan on street parking pada ruas Jalan Damar Padang dibuktikan dengan hasil penilaian Indeks Parkir di kawasan kajian.

\section{Kapasitas Ruang Parkir}

Kapasitas ruang parkir merupakan banyak kendaraan yang dapat di tampung pada lahan parkir dengan waktu tertentu (Purbanto, 2012). Semakin lama suatu kendaraan parkir semakin maka semakin sedikit kapasitas ruang parkir yang tersedia untuk melayani kebutuhan ruang parkir demikian pula sebaliknya. Perhitungan kapasitas ruang parkir yang tersedia untuk melayani kebutuhan parkir pada ruas Jalan Damar Padang dapat dilihat pada Tabel 7.

Tabel 7. Kapasitas Ruang Parkir

\begin{tabular}{cccccc}
\hline Lokasi Parkir & Hari & Jumlah Petak & $\begin{array}{c}\text { Durasi Parkir Rata } \\
- \text { Rata } \\
\text { ( Jam/Kend })\end{array}$ & $\begin{array}{c}\text { Kapasitas Ruang } \\
\text { Parkir } \\
\text { ( Kend/Jam })\end{array}$ & $\begin{array}{c}\text { Kapasitas Parkir } \\
\text { Rata -Rata } \\
\text { (Kend/Jam) }\end{array}$ \\
\hline Ruas Kiri & Rabu & & 0.69 & 44.72 & \\
(Veteran - & Sabtu & 31 & 0.69 & 45.19 & 57.65 \\
Pemuda) & Minggu & & 0.37 & 83.06 & \\
Ruas Kanan & Rabu & & 0.50 & 106.63 & \\
(Veteran - & Sabtu & 53 & 0.64 & 83.04 & \\
Pemuda) & Minggu & & 0.55 & 96.27 & \\
\hline
\end{tabular}

Sumber : Hasil Analisa Data Survei, 2019 
Dengan tersedianya 53 petak pada sisi kanan, maka ruas jalan Damar (kanan) tersebut akan mampu menampung rata-rata sebanyak 96 kendaraan/jam (Tabel 7). Ditambah pula dengan tersedianya 31 petak pada sisi kiri, maka ruas jalan Damar (kiri) tersebut akan mampu menampung rata-rata sebanyak 58 kendaraan/jam.

\section{Pengendalian on Street parking pada lokasi studi}

Pengelolaan parkir dikawasan kajian telah diupayakan secara off street, menggunakan automated machine yang dikelola pihak swasta. Namun pengendara roda empat cenderung parkir on street dengan durasi parkir kendaraan rata-rata 35-36 menit. Maka pengendalian parkir on street yang mungkin dilakukan di ruas Jalan Damar Padang adalah dengan membangun fasilitas alat meter parkir, seperti yang pernah dilaporkan sukses di beberapa kota di Indonesia (KPPN, 2012). Ruas Jalan Damar yang direkomendasikan untuk diterapkan alat pengendali meter parking system adalah sepanjang \pm 265 meter (4 lajur 2 arah). Berdasarkan hasil analisis field survey (Jalan Veteran - Jalan Pemuda), pengguna cenderung memarkirkan kendaraan dengan pola paralel atau sejajar di ruas kiri. Maka perkiraan petak parkir yang dapat disusun adalah sebanyak 31 petak parkir pada sisi kiri. Sedangkan di ruas kanan, aktivitas on street parking jauh lebih padat, sehingga pola parkir sudut $90^{\circ}$ akan menghasilkan susunan 53 petak parkir. Dengan pola tersebut dapat disusun secara bersama sebanyak 84 petak parkir di sepanjang ruas Jalan Damar. Sesuai aturan satuan ruang parkir mobil (MKJI, 1997), penulis merekomendasikan lay out parkir (Gambar 6)

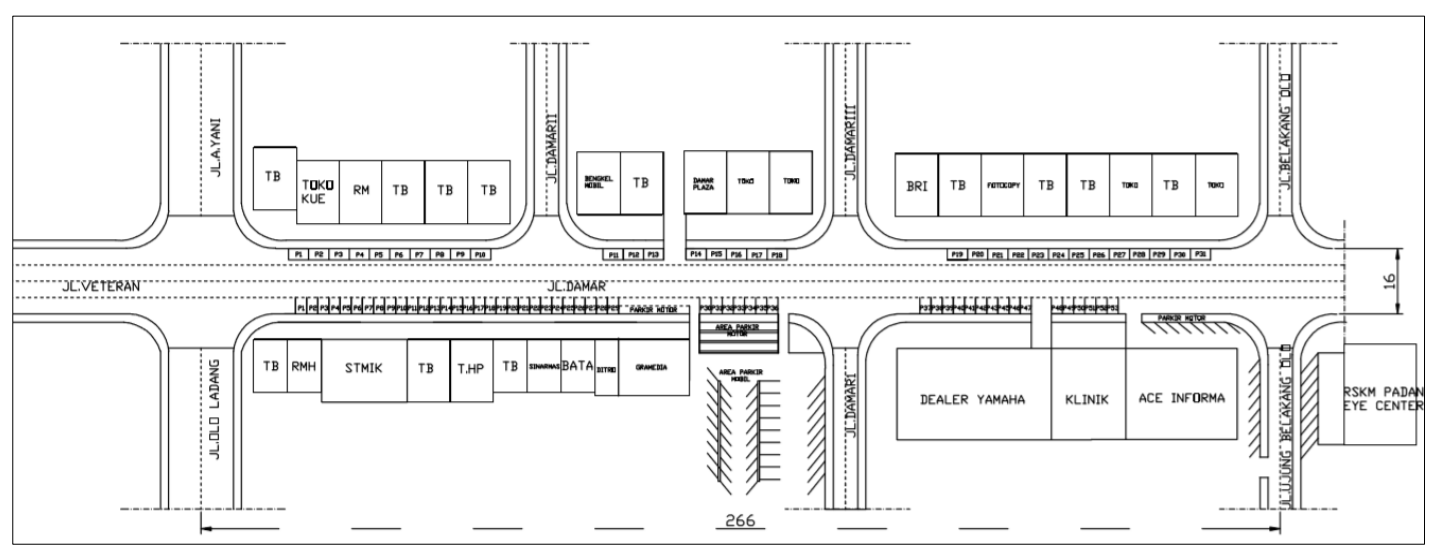

Gambar 6. Rekomendasi Lay Out Parkir

(Sumber : Survei Lapangan, 2019)

\section{KESIMPULAN}

1. Volume parkir maksimum terjadi hari Minggu dengan total 264 kendaraan parkir. Durasi parkir rata-rata kendaraan roda empat pada ruas Jalan Damar berlangsung selama 34-35 menit. Menurut rencana lay out parking Ruas Jalan Damar, dapat disusun 84 petak parkir, 53 petak pada ruas kanan (arah Jl.Veteran - Jl.Pemuda) dan 31 petak pada ruas kiri. Tingkat 
Turn Over parkir kendaraan roda empat maksimum terjadi pada ruas kanan (Minggu) sebesar 3,64 kend/hari/ruang.

2. Perlu pertimbangan lain seperti variabel tarif, pendapatan parkir, walking distance, dan pertumbuhan laju kendaraan dalam analisis lanjutan potensi pengendalian on street parking dengan alat mesin meter di kawasan kajian.

\section{DAFTAR PUSTAKA}

Cook, J., Simonson, J. 2012. Parking Rates Show Modest Growth. 2012 Parking Rates Survey. Colliers International.

Daniels, R., Mulley, C. 2013. Explaining walking distance to public transport: The dominance of public transport Supply. The Journal of Transport and Land Use, Vol. 6 No.2, 2013. pp. 5-20. doi: 10.5198/jtlu.v6i2.308. http://jtlu.org

Guvil, Q., Birman, R. B., Roza, A. 2018. Deskriptif Karakteristik Ruang Parkir Pasca Penggunaan Mesin Meter Parkir (Studi Kasus: Ruas Jalan Permindo Kota Padang). $\begin{array}{llllll}\text { Jurnal Ilmiah Rekayasa Sipil, } & \text { Vol } & 15 & \text { No } & 1, & 2018 .\end{array}$ http://ejournal.polinpdg.ac.id/index.php/JRS/issue/view/27

Hobbs, 1995. Hobbs, F.D, 1995, Perencanaan dan Teknik Lalu Lintas, Penerbit Gadjah Mada University Press.

Kementrian Perencanaan Pembangunan Nasional (KPPN), 2015. Toolkit untuk Mobilitas Perkotaan di Indonesia Manajemen Parkir Di Perkotaan. GIZ - Sustainable Urban Transport Improvement Project (SUTIP) Deutsche Gesellschaft für Internationale Zusammenarbeit (GIZ).

Jakarta. http://www.transportindonesia.org/WebPublications/Toolkits/GIZ\%20SUTIP\%20T oolkit\%20Manajemen\%20Parkir.pdf

Manual Kapasitas Jalan Indonesia. 1997.

Moore, R.J. Parking Rates, 2009. Global CBD Parking Rates Survey. Colliers International. Purbanto I Gusti Raka, 2012. Karakekteristik Parkir Pinggir Jalan (On Street Parking) Dan Pengaruhnya Terhadap Kinerja Ruas Jalan, Universitas Udayana.

Roza, A., Guvil, Q., Birman, R., B. 2018. Analisis kinerja ruas jalan akibat on - street parking system pasca pemasangan alat meter parkir (studi kasus ruas jalan permindo kota padang). Jurnal Teknik Sipil ITP, Vol. 5 No. 2 Juli 2018, Hal. 62-76. https://ejournal.itp.ac.id/index.php/tsipil/issue/view/98 